Titulo do Trabalho

\title{
PATRIMÔNIO CULTURAL FERROVIÁRIO E A IMPORTÂNCIA DE SUA PROTEÇÃo
}

Nome do Autor (a) Principal

\section{Luis Gustavo Bonora Vidrih Ferreira}

Nome (s) do Coautor (a) (s)

Gabriel Luis Bonora Vidrih Ferreira

Nome (s) do Orientador (a) (s)

Gabriel Luis Bonora Vidrih Ferreira

Instituição ou Empresa

USP / UEMS

E-mail de contato

gustavovidrih@usp.br

Palavras-chave

Patrimônio cultural. Patrimônio Ferroviário. Legislação.

INTRODUÇÃO

A relevância acerca da proteção ao patrimônio cultural industrial adquiriu maiores proporções no período após a Segunda Guerra mundial, em razão dos efeitos destrutivos do conflito ensejando uma maior preocupação com os remanescentes do processo de industrialização (SANTOS, 2011).

Em que pese a existência de atenção ao legado do processo de industrialização já no século XIX, Kuhl (2010) enfatiza que as iniciativas de preservação se tornaram mais sistemáticas a partir dos anos 60 em decorrência das discussões surgidas após a 
destruição de edifícios significativos como a Bolsa de Carvão e da Estação Euston em Londres, no início dos anos 1960, e do Mercado Central de Paris, no início dos anos 1970.

Segundo Silva (2010) as origens do conceito de patrimônio industrial remontam ao surgimento do termo arqueologia industrial, popularizado por Michel Rix, nos anos $50 \mathrm{e}$ aceito na década de 60 como área de estudo que não se centrava apenas na vertente material do patrimônio cultural, mas considera também "os parâmetros sociais e culturais que definiam a sociedade industrial".

Desde então, a temática do patrimônio industrial passou a receber uma maior atenção, seja em nível nacional ou internacional. Neste sentido, merece destaque a Carta de Nizhny Tagil, editada em 2003 pelo TICCIH (The Internacional Committee for the Conservation of the Industrial Heritage) que prescreve o conceito de patrimônio industrial como aquele composto "dos restos da cultura industrial que possuam um valor histórico, tecnológico, social, arquitetônico ou científico", os quais poderão consistir em edifícios, maquinaria, escritórios, moinhos, fábricas, minas e lugares para processar e refinar, armazéns e depósitos, lugares onde se gera, se transmite e se usa energia, meios de transporte e toda sua infra-estrutura, assim como os lugares onde se desenvolvem as atividades sociais relacionadas com a indústria, tais como as moradias, o culto religioso ou a educação. $O$ documento ainda ressalta o fato de que a arqueologia industrial "configurase como vasto campo temático que exige a articulação de várias disciplinas, não sendo possível formar uma figura profissional que domine todos os instrumentos necessários" (KUHL, 2010).

\section{OBJETIVO GERAL}

- O presente trabalho tem como objetivo geral identificar os fundamentos e a importância da proteção ao Patrimônio Cultural, em sua vertente ferroviária, destacando o testemunho material e imaterial que evocam destes bens e as iniciativas legais para sua conservação.

\section{OBJETIVOS ESPECÍFICOS}


- Destacar o processo histórico de reconhecimento do patrimônio cultural industrial;

- Caracterizar o Patrimônio Cultural Ferroviário reconhecendo suas especificdades; e

- Analisar os instrumentos legais específicos em relação ao patrimônio ferroviário e a atuação do IPHAN neste sentido.

\section{METODOLOGIA}

Para subsidiar o estudo, utilizou-se das técnicas de pesquisa documental e pesquisa bibliográfica, com análise dos dispositivos legais aplicáveis além de trabalhos técnicos e científicos que se relacionam com a temática.

\section{RESULTADO(S)}

Em razão da influência inglesa no modelo de transporte de carga e passageiros no Brasil, consolidou-se em nosso país um "extenso, complexo, diverso e, ao mesmo tempo, único modus operandi ligado ao contexto das ferrovias" implementando-se em diversas cidades toda uma gama de estruturas compostas por estações, armazéns de carga, oficinas, pátios e complexos ferroviários (FREIRE et al, 2012).

Destaca-se, neste processo, a criação, em 1957 da Rede Ferroviária Federal Sociedade Anônima (RFFSA), por meio da reunião várias ferrovias com o objetivo reestruturar e ampliar o transporte ferroviário no Brasil.

De acordo com Monastirsky (2006) o reconhecimento das ferrovias e seus aparatos como elementos integrantes do patrimônio cultural sustenta-se através da memória coletiva associada às memórias individuais levando em conta que o patrimônio cultural ferroviário se mostra composto pelas categorias de patrimônio material, com destaque para as estações e locomotivas antigas, e patrimônio imaterial evocando aspectos e elementos relacionados às memórias sensoriais e ao modo de vida da sociedade.

Deste modo, a chamada memória ferroviária pode ser compreendida como toda forma de suporte e informações relacionadas ao contexto ferroviário brasileiro, em especial aqueles de ordem documental-bibliográfica, iconográfica, histórica, arquitetônico- 
urbanística (no contexto do complexo ferroviário ou quanto a paisagem) e sociológica (FREIRE et al, 2012).

Com a inclusão da RFFSA no Programa Nacional de Desestatização em 1992, iniciou-se um processo de transferência dos serviços de transporte ferroviário de carga para a iniciativa privada que ensejou no desuso de inúmeras estações ferroviárias que passaram a ser objeto de deterioração e depredação (CAVALCANTI NETO et al, 2012), culminando em sua extinção em 2007.

Em manifesta preocupação com o resguardo do patrimônio ferroviário, a Lei noำ 11.483 fixou a atribuição do IPHAN para receber a administrar os bens móveis e imóveis de valor artístico, histórico e cultural, advindos da extinta RFFSA, zelando por sua guarda e manutenção. No caso de bens qualificados como operacionais, o seu compartilhamento para uso ferroviário precisará ser garantido pelo IPHAN.

Conforme assevera Cavalcanti Neto et al (2012), dados preliminares da extinta RFFSA, em 2007, indicam que o patrimônio ferroviário seria representado "por 52.000 bens imóveis, 15.000 bens classificados pela RFFSA como históricos, 31.400 metros lineares de acervo documental, 118.000 desenhos técnicos, 74.000 itens bibliográficos, e um incalculável número de bens móveis espalhados nos escritórios regionais da RFFSA, em almoxarifados, depósitos e pátios".

Em virtude da variedade de bens de interesse cultural, com vistas a ofertar maior flexibilidade à ação pública de conservação deste patrimônio, em 2010 o IPHAN editou a Portaria no 407 prescrevendo o procedimento relativo à valoração, gestão e administração dos bens ferroviários e implantando a "Lista do Patrimônio Cultural Ferroviário", onde passaram a ser inscritos todos os bens reconhecidos como detentores de valor artístico, histórico e cultural.

A referida Lista do Patrimônio Cultural Ferroviário representa um novo instrumento de preservação cultural cuja operacionalidade traz maior desenvoltura para a atuação do IPHAN neste contexto em razão do instituto do tombamento se mostrar de complexa viabilidade para o amplo acervo de bens a serem tutelados.

\section{CONCLUSÕES}


O patrimônio industrial não se refere apenas à salvaguarda do recinto produtivo, da fábrica, mas sim de como esse modelo de produção se apoderou do sítio urbano e como sua estruturação se articula às outras atividades, envolvendo aspectos sociais, culturais, econômicos e políticos. Por vezes isso se trata de todo um complexo paisagístico.

No entanto, a ação governamental de conservação deste patrimônio foi marcada, durante muito tempo, por uma postura isolada, com a preservação incidindo apenas em relação ao aspecto material do patrimônio. Do mesmo modo, os processos de tombamento se destacavam pelo atraso em sua efetivação em relação à velocidade de depredação e demolição desses bens, não possibilitando "a constituição de uma representação que sintetize materialmente o processo histórico de construção do território e das relações sociais, fator essencial para fornecer ao cidadão uma forma de perceber o passado como um tempo integrante de sua vida" (RODRIGUES, 2010).

Neste sentido, considera-se que a perspectiva de proteção ao patrimônio cultural ferroviário no Brasil, em que pese a necessidade de maiores avanços, sofreu significativa evolução ao longo do tempo, destacando-se neste processo a iniciativa do IPHAN de criar a "Lista do Patrimônio Cultural Ferroviário".

\section{REFERÊNCIAS}

CAVALCANTI NETO, J. R. et al. Avanços e desafios na preservação do patrimônio ferroviário pelo instituto do patrimônio histórico e artístico nacional. Disponível em <http://portal.iphan.gov.br/portal/baixaFcdAnexo.do?id=2995>. Acesso em: 15 set. 2013.

FREIRE, M. E. L. et al. Patrimônio ferroviário: memória ou esquecimento? Abordagem conceitual no processo de valoração do patrimônio ferroviário em Pernambuco. Disponível em <http://portal.iphan.gov.br/portal/baixaFcdAnexo.do?id=2999>. Acesso em: 15 set. 2013.

KUHL, B. M. Patrimônio industrial: algumas questões em aberto. Revista Arq.Urb, São Paulo, n.3, p.23-30, 2010. 
MONASTIRSKY, L. B. Ferrovia: patrimônio cultural. Estudo sobre a ferrovia brasileira a partir da região dos Campos Gerais (PR). 2006. 190f. Tese (Doutorado em Geografia) - Centro de Filosofia e Ciências Humanas, Universidade Federal de Santa Catarina, Florianópolis. 2006

RODRIGUES, M. Patrimônio Industrial, entre o fetiche e a memória. Revista Eletrônica de Arquitetura e Urbanismo - Universidade São Judas Tadeu, São Paulo, n.3, p.31-40, 2010.

SANTOS, R. M. A. Análise tipológica e o patrimônio industrial: um estudo de fábricas doceiras na zona rural de Pelotas, RS. 2011. 246 f. Tese (Mestrado em Memória Social e Patrimônio Cultural), Universidade Federal de Pelotas, Pelotas. 2011

DA SILVA, R. A. R. Paisagem Cultural Industrial: memórias de um patrimônio da contemporaneidade. Disponível em <http://conpadre.org/c2010_papers/paper_77.pdf >. Acesso em 15 set. 2013. 